\title{
Favorable effect of mycorrhizae on biomass production efficiency exceeds their carbon cost in a fertilization experiment
}

\author{
Melanie S. Verlinden, ${ }^{1,3}$ Arne Ven, ${ }^{1}$ Erik Verbruggen, ${ }^{1}$ Ivan A. Janssens, ${ }^{1}$ Håkan Wallander,${ }^{2}$ and Sara Vicca ${ }^{1}$ \\ ${ }^{1}$ Research Centre of Excellence Plants and Ecosystems, University of Antwerp, Wilrijk BE-2610 Belgium \\ ${ }^{2}$ Department of Biology, Lund University, Lund 22362 Sweden
}

\begin{abstract}
Biomass production efficiency (BPE), the ratio of biomass production to photosynthesis, varies greatly among ecosystems and typically increases with increasing nutrient availability. Reduced carbon partitioning to mycorrhizal fungi (i.e., per unit photosynthesis) is the hypothesized underlying mechanism, as mycorrhizal abundance and plant dependence on these symbionts typically decrease with increasing nutrient availability. In a mesocosm experiment with Zea mays, we investigated the effect of nitrogen $(\mathrm{N})$ and phosphorus $(\mathrm{P})$ addition and of mycorrhizal inoculation on BPE. Photosynthesis and respiration were measured at mesocosm scale and at leaf scale. The growth of arbuscular mycorrhizal fungi (AMF) was assessed with ingrowth bags while also making use of the difference in $\delta^{13} \mathrm{C}$ between $\mathrm{C}_{4}$ plants and $\mathrm{C}_{3}$ soil. Mesocosms without $\mathrm{AMF}$, that is, with pasteurized soil, were used to further explore the role of AMF. Plant growth, photosynthesis, and BPE were positively affected by $\mathrm{P}$, but not by $\mathrm{N}$ addition. AMF biomass also was slightly higher under $\mathrm{P}$ addition, but carbon partitioning to AMF was significantly lower than without $\mathrm{P}$ addition. Interestingly, in the absence of AMF, plants that did not receive $\mathrm{P}$ died prematurely. Our study confirmed the hypothesis that BPE increases with increasing nutrient availability, and that carbon partitioning to AMF plays a key role in this nutrient effect. The comparison of inoculated vs. pasteurized mesocosms further suggested a lower carbon cost of nutrient uptake via AMF than via other mechanisms under nutrient rich conditions.
\end{abstract}

Key words: arbuscular mycorrhizae; biomass production efficiency; carbon allocation; carbon use efficiency; mesocosm experiment; nitrogen; nutrient availability; phosphorus.

\section{INTRODUCTION}

The sequestration of carbon (C) into plants and soil currently mitigates climate change (Le Quéré et al. 2016). The C residence time in an ecosystem, which is a principal determinant of its $\mathrm{C}$ sink strength, depends strongly on the $\mathrm{C}$ partitioning (i.e., allocation relative to gross photosynthesis) pattern, and particularly on how much of the $\mathrm{C}$ assimilated during photosynthesis is used for plant biomass production vs. respiration. The $\mathrm{C}$ partitioning to plant biomass production, referred to as biomass production efficiency (BPE, i.e., the ratio of biomass production to photosynthesis), varies greatly among ecosystems. Some ecosystems use only $30 \%$ of their photosynthates for plant growth, while others use up to 70\% (DeLucia et al. 2007, Litton et al. 2007, Vicca et al. 2012, Raich et al. 2014). A potentially large but typically neglected fraction of GPP (up to 30\%; Hobbie 2006) can be allocated to symbionts such as mycorrhizal fungi, and this fraction likely decreases with increasing nutrient availability (Lilleskov et al. 2002, Treseder 2004, Vicca et al. 2012) as plants then need to invest less in nutrient acquisition.

Various factors have been proposed to explain the large variation in BPE, including climate and plant age (DeLucia et al. 2007), but evidence is growing that nutrient availability plays a key role (Vicca et al. 2012, Buendía et al. 2014). BPE has been shown to decrease with decreasing nutrient availability (Vicca et al. 2012), but the underlying mechanisms

Manuscript received 13 March 2018; revised 12 June 2018; accepted 27 July 2018. Corresponding Editor: Christine Hawkes.

33-mail: Melanie.Verlinden@uantwerpen.be remain unclear. The two most probable reasons are a shift in $\mathrm{C}$ partitioning toward autotrophic respiration, or, a shift in $\mathrm{C}$ partitioning to symbionts. The influence of nutrient availability on $\mathrm{C}$ partitioning to plant respiration is still poorly understood, but the respiration-to-photosynthesis ratio of leaves appears relatively constant across species and ecosystem types (Reich et al. 1998, Loveys et al. 2003, Turnbull et al. 2005, Atkin et al. 2007, Campbell et al. 2007). These observations are in line with the theory that plants respire a relatively constant fraction of their gross primary production (GPP; Dewar et al. 1998, van Oijen et al. 2010) due to interdependencies of respiration and photosynthesis (Hoefnagel et al. 1998).

On the other hand, nutrient availability most likely determines how much C plants allocate to their symbionts (Smith and Read 2008). Mycorrhizal fungi are associated with some $80 \%$ of land plants (Smith and Read 2008) and may consume a large fraction of the $\mathrm{C}$ available for biomass production (Courty et al. 2010). However, they are typically neglected in $\mathrm{C}$ cycle studies because of major difficulties assessing their growth, especially in natural conditions (Wallander et al. 2013). Although accurate quantification of mycorrhizal $\mathrm{C}$ use in the field is difficult (Staddon et al. 2003, Olsson and Johnson 2005), it is more feasible in mesocosm experiments, where $\mathrm{C}$ fluxes can be monitored more precisely.

We set up a mesocosm nutrient manipulation experiment with maize (Zea mays L.), a $\mathrm{C}_{4}$ plant, growing on $\mathrm{C}_{3}$ soil in which we (1) expected shifts in BPE due to soil nutrient availability (nitrogen, N, and phosphorus, P) and (2) expected that this shift was not linked to autotrophic 
respiration, but to mycorrhization. For the latter, we focused on autotrophic respiration and on the growth of mycorrhizal fungi, which was estimated by using the naturally occurring difference in $\delta^{13} \mathrm{C}$ between $\mathrm{C}_{4}$ plants and $\mathrm{C}_{3}$ soil. We hypothesized that increasing nutrient availability increases BPE due to reduced investment in mycorrhizae rather than to reduced plant respiration.

\section{Materials AND Methods}

\section{Experimental design}

A fertilization ( $\mathrm{N}$ and $\mathrm{P}$ ) experiment, consisting of 30 mesocosms ( $1 \mathrm{~m} \times 1.2 \mathrm{~m}, 0.6 \mathrm{~m}$ high insulated containers $)$, was established in a greenhouse in Sint-Katelijne-Waver, Belgium (5104'38" N, 432'05" E). In April 2016, all mesocosms were filled with nutrient-poor soil, which was a homogenized mixture of (1) sandy soil (Arenosol) originating from a pine forest in a nature reserve in Belgium with a texture of $95 \%$ sand and 5\% silt, (2) white river sand, and (3) a minor fraction of potting soil, mixed in a proportion of $72 \%, 23 \%$, and $5 \%$ by volume, respectively. The potting soil consisted of a mixture of peat, perlite, and fertilizers (NPK $\left.14-16-18 ; 1.5 \mathrm{~kg} / \mathrm{m}^{3}\right)$. Lime was added to increase the $\mathrm{pH}$ of the soil to an average of 6.84 (standard error (SE) of \pm 0.14 ) at the onset of the experiment. The mixture had a bulk density of on average $1.379 \pm 0.006 \mathrm{~g} / \mathrm{cm}^{3}$ and a water saturation value, field capacity, and permanent wilting point of $41.5 \% \pm 0.7 \%, 6.5 \% \pm 0.2 \%$, and $0.7 \% \pm 0.1 \%$ by volume, respectively.

On 20 May 2016, 12 seedlings of maize (Zea mays L., variety "Tom Thumb") were transplanted into each mesocosm (i.e., a plant density of 10 plants $/ \mathrm{m}^{2}$ ). Seeds had been set to germinate one week earlier on water-saturated cotton at ambient (room) temperature. The $\mathrm{N}$ treatment was fertilized with calcium nitrate at a rate of $95.5 \mathrm{~kg} \mathrm{~N} / \mathrm{ha}$ (YaraLiva Calcinit; Yara B.V., Rotterdam-Vlaardingen, The Netherlands); the $\mathrm{P}$ treatment received $20 \mathrm{~kg} \mathrm{P} / \mathrm{ha}$ as triple superphosphate (Janssens-Smeets, Moerdijk, The Netherlands); the combined $\mathrm{N}$ and $\mathrm{P}$ treatment (NP) received the combined amount of these nutrients. $\mathrm{N}$ and $\mathrm{P}$ fertilization rates were derived from the nutrient requirements for maize (Roy et al. 2006). Due to the higher amount of calcium in the $\mathrm{N}$ fertilizer, calcium was compensated for in the control and $\mathrm{P}$ treatments. All mesocosms, including the control treatment, received a basic dose of micronutrients (Fertigreen Patentkali [Yara B.V.] and GroGreen [Lima Europe NV, Rumst, Belgium] containing $79 \mathrm{~kg} / \mathrm{ha} \mathrm{K}, 19 \mathrm{~kg} / \mathrm{ha} \mathrm{Mg}, 53 \mathrm{~kg} / \mathrm{ha} \mathrm{S}$, $0.4 \mathrm{~kg} / \mathrm{ha} \mathrm{B}, 0.1 \mathrm{~kg} / \mathrm{ha} \mathrm{Cu}, 2.4 \mathrm{~kg} / \mathrm{ha} \mathrm{Fe}, 1.1 \mathrm{~kg} / \mathrm{ha} \mathrm{Mn}, 0.1$ $\mathrm{kg} / \mathrm{ha}$ Mo, $0.4 \mathrm{~kg} / \mathrm{ha} \mathrm{Zn}$ ). Each treatment consisted of five replicates.

Spore-based inoculum of arbuscular mycorrhizal fungi (AMF; species Rhizophagus irregularis (Blaszk., Wubet, Renker and Buscot) C. Walker and A. Schüßler; Symplanta, Oldenburg, Germany) was added to 20 (four nutrient treatments $\times$ five replicates) mesocosms. In order to verify responses also in the absence of mycorrhizal fungi, the soil in 10 of the 30 mesocosms (five control and five NP) was pasteurized prior to planting and fertilizer application. To this end, the soil was heated at $80^{\circ} \mathrm{C}$ for $4 \mathrm{~h}$. No inoculum was added to these mesocosms. Fertilizer addition in these pasteurized mesocosms was the same as described for the NP and control treatments. Soil moisture was monitored in all mesocosms, and water was regularly added to maintain soil moisture at $80-100 \%$ of field capacity.

\section{Measurements}

Environmental variables.-Photosynthetic Active Radiation (PAR) and soil temperature were continuously logged from PAR sensors (JYP 1000, SDEC, Reignac-sur-Indre, France) and two soil temperature sensors (NTC-WH probe, Carel Industries, Manheim, Pennsylvania, USA) installed in each mesocosm. Air temperature was logged simultaneously from a centralized air thermometer in the greenhouse. Soil water content (SWC) was logged continuously from a water content reflectometer (CS616, Campbell Scientific, Logan, Utah, USA) installed in each mesocosm. Soil nutrient availability was monitored twice during the growing season (July and August) with plant root simulator resin probes (PRS, Western Ag Innovations, Saskatoon, Saskatchewan, Canada). The probes were inserted into the soil during one week before being analyzed, providing a dynamic measure of nutrient availability (e.g., Dijkstra et al. 2012, May et al. 2012).

$\mathrm{CO}_{2}$ fluxes.-Mesocosm photosynthesis and respiration were quantified by chamber measurements of $\mathrm{CO}_{2}$ fluxes, conducted seven times during the season, that is, every two to three weeks. A transparent cuvette covering the entire mesocosm was coupled to an EGM-4 infrared gas analyzer (PP Systems, Hitchin, UK) to measure the $\mathrm{CO}_{2}$ flux during $200 \mathrm{~s}$, operating as a dynamic closed system (De Boeck et al. 2007, Vicca et al. 2007). Net ecosystem (mesocosm) exchange (NEE) was estimated from measurements at a range of light intensities (as in, e.g., Vicca et al. 2007) between 0 and $1,300 \mu \mathrm{mol} \cdot \mathrm{m}^{-2} \cdot \mathrm{s}^{-1}$ of PAR using cloths of different transparency covering the mesocosm, attenuating incoming light. The $\mathrm{CO}_{2}$ effluxes in a fully darkened cuvette represented total mesocosm $\mathrm{CO}_{2}$ efflux $\left(R_{\text {eco }}\right)$. GPP was then estimated by summing NEE and $R_{\text {eco. }}$ Autotrophic respiration $\left(R_{\text {aut }}\right)$ was estimated as the residual $\mathrm{C}$ needed to close the $\mathrm{C}$ balance, that is, by subtracting $\mathrm{C}$ allocated to plant biomass, AMF, and root exudates (see Mycorrhizal fungi.) from GPP.

For each measurement campaign of mesocosm-scale fluxes, GPP data at various light intensities were pooled per treatment and light response curves were fitted using Eq. 1:

$$
\mathrm{GPP}=\left(\mathrm{QE} \cdot \mathrm{GPP}_{\max } \cdot \mathrm{PAR}\right) /\left(\mathrm{QE} \cdot \mathrm{PAR}+\mathrm{GPP}_{\max }\right)
$$

in which QE is the quantum efficiency and GPP $\max$ the maximum photosynthesis. GPP was subsequently upscaled over time by combining these biweekly curves with the logged PAR of the corresponding periods and summed to obtain total growing season GPP. Standard error of the sum was calculated via error propagation. A similar procedure was followed for seasonal $R_{\text {eco }}$, for which the temperature response of $R_{\text {eco }}$ was fitted using the $Q_{10}$ function (Eq. 2)

$$
R_{\mathrm{eco}}=R_{22} \cdot Q_{10}^{((T-22) / 10))}
$$

where $R_{22}$ is the reference mesocosm respiration at $22^{\circ} \mathrm{C}$ (mean air temperature over the measurement period), $Q_{10}$ is 
the temperature sensitivity, and $T$ is the air temperature in ${ }^{\circ} \mathrm{C}$. Logged air temperature was used to scale up $R_{\text {eco }}$ to a mean seasonal value. BPE was estimated as the fraction of final biomass to seasonally cumulative GPP.

As a complement to the mesocosm-scale chamber measurements, respiration and photosynthesis were measured also at leaf scale. A portable LI-COR gas exchange system LI-6400 (Biosciences, Lincoln, Nebraska, USA) was used, operating as an open system. Net $\mathrm{CO}_{2}$ assimilation rate was measured at $22^{\circ} \mathrm{C}$ and photosynthetic photon flux densities of $1,200 \mu \mathrm{mol} \cdot \mathrm{m}^{-2} \cdot \mathrm{s}^{-1}$ (considered as maximal assimilation rate; $A_{\max }$ ) and $0 \mu \mathrm{mol} \cdot \mathrm{m}^{-2} \cdot \mathrm{s}^{-1}$ (net assimilation at zero light, considered as "respiration in the dark" $\left.\left[R_{\text {dark }}\right]\right)$. The ratio $R_{\text {dark }} / A_{\text {max }}$ served as an indication of the fraction of photosynthates used in plant respiration.

Plant biomass measurements and plant tissue $P$ concentration.-On 22 August 2016, when plant growth had stopped and corn cobs had ripened, both above- and belowground biomass were harvested. All aboveground biomass was harvested in each mesocosm; belowground biomass was sampled by taking six cores $(7 \mathrm{~cm}$ diameter) down to the approximate rooting depth of $30 \mathrm{~cm}$. To approach a spatially representative estimate of root biomass, two cores were collected on a stubble and the remainder at variable distances between the stubbles. Soil cores were sieved and roots were washed manually. Biomass was oven dried for $72 \mathrm{~h}$ at $70^{\circ} \mathrm{C}$, its $\mathrm{C}$ concentration was determined using an elemental analyzer (model FLASH 2000; Thermo Fisher Scientific, Waltham, Massachusetts, USA). The $\mathrm{P}$ concentration of leaves, stalks, roots, and cobs were determined separately by digestion in tubes with $\mathrm{H}_{2} \mathrm{SO}_{4}$-salicylic acid- $\mathrm{H}_{2} \mathrm{O}_{2}$ and selenium (Temminghoff and Houba 2004).

Mycorrhizal fungi.-Mycorrhizal colonization was verified in July and August by sampling roots from two plants per mesocosm. Per plant, $20 \mathrm{~cm}$ of one lateral root containing root hair, was excavated, cut, and stored for maximal $2 \mathrm{~d}$ at $5^{\circ} \mathrm{C}$. These roots were cleared and stained using a non-vital staining technique (as described by Vierheilig et al. 2005), using a $5 \% \mathrm{KOH}$ solution and a Sheaffer Black Ink solution (10\% ink in a $10 \%$ acetic acid solution). Mycorrhizal colonization was quantified by counting arbuscules, vesicules, and hyphae applying the gridline intersection method (Giovannetti and Mosse 1980, Brundrett et al. 1996, Vierheilig et al. 2005).

To estimate $\mathrm{C}$ allocation to $\mathrm{AMF}$, we used the $\mathrm{C}_{3} / \mathrm{C}_{4}$ isotopic shift method with a $\mathrm{C}_{4}$ species (Zea mays) planted on $\mathrm{C}_{3}$ soil (Balesdent et al. 1987, Kuzyakov 2006) in combination with the mesh bag approach to quantify ingrowth of mycorrhizal fungi (see Wallander et al. 2013). The latter involves installing mesh bags $(10 \mathrm{~cm}$ length, $2 \mathrm{~cm}$ diameter, and pore size $30 \mu \mathrm{m}$ to prevent ingrowth of roots) that are filled with carbon-free sand. Because $\mathrm{C}_{4}$ plants are richer in ${ }^{13} \mathrm{C}$ than $\mathrm{C}_{3}$ vegetation and the organic matter it produces, and because AMF but not roots can grow into the mesh bags, the plant-derived $\mathrm{C}$ in the mesh bags was assumed to originate primarily from AMF biomass, although root exudates probably also contribute to that signal.

Mesh bags were installed at the time of planting and harvested at the end of the season. The $\mathrm{C}$ concentration and stable isotope composition of the mesh bag content (sand plus fungal biomass) were analyzed with Elemental Analysis Isotope Ratio Mass Spectrometry (EA-IRMS; CE Instrument EA 1110 elemental analyzer, coupled to a Finnigan MAT DeltaPlus IRMS with a Finnigan MAT ConFlo II Interface; Thermo Fisher Scientific, Bremen, Germany).

The fraction of plant-derived $\mathrm{C}\left(\mathrm{fC}_{4}\right)$ in mesh bag soil $(\mathrm{mb})$ was calculated using a two-ended linear mixing model assuming the $\delta^{13} \mathrm{C}$ of the AMF equals that of the roots $\left(\delta^{13} \mathrm{C}\right.$ roots) and that any $\mathrm{C}$ that may have entered the mesh bags (e.g., saprotrophic fungi or dissolved organic $\mathrm{C}$ released during decomposition in the surrounding soil) has the $\delta^{13} \mathrm{C}$ signal of the initial SOM $\left(\delta^{13} \mathrm{C}\right.$ SOM $)$

$$
\mathrm{fC}_{4}=\left(\delta^{13} \mathrm{C}_{\mathrm{mb}}-\delta^{13} \mathrm{CSOM}\right) /\left(\delta^{13} \mathrm{C} \text { roots }-\delta^{13} \mathrm{C} \mathrm{SOM}\right) .
$$

Total plant derived $\mathrm{C}$ in mesh bags was then calculated as

$$
\text { plant-derived } \mathrm{C} \text { in mesh bags }=\mathrm{fC}_{4} \cdot \mathrm{C}_{\mathrm{mb}}
$$

where $\mathrm{C}_{\mathrm{mb}}$ is the $\mathrm{C}$ content of the mesh bag.

We used this plant-derived $\mathrm{C}$ also to calculate a proxy for the $\mathrm{P}$ acquisition cost as the total plant $\mathrm{P}$ content (i.e., plant tissue $\mathrm{P}$ concentrations multiplied by tissue biomass) relative to the sum of root- and plant-derived $\mathrm{C}$, expressed as $\mathrm{g} \mathrm{C}$ per $\mathrm{g}$ P. Because root exudates may also enter the mesh bags, we further verified the plant-derived $C$ estimate by analyzing the PLFA 16:1 15 in the mesh bags. PLFA $16: 1 \omega 5$ is indicative of AMF hyphal biomass (Olsson and Johansen 2000), and a correlation between AMF-C and these the PLFA $16: 1 \omega 5$ would thus confirm that the plant-derived $C$ in the mesh bags is indeed primarily AMF derived. As prescribed in, e.g., Birgander et al. (2017), lipids were extracted from freeze-dried soil using a one-phase mixture of chloroform, methanol, and citrate buffer were separated into PLFAs and NLFAs on prepacked silica columns (Van Aarle and Olsson 2003). The fatty acid methyl esters (FAMEs) resulting from mild alkaline methanolysis were analyzed by gas chromatography using FAME 19:0 as internal standard (Frostegård et al. 1993).

\section{Statistical analysis}

Data normality and homoscedasticity were checked using the Shapiro-Wilk and Levene's test respectively. A two-way analyses of variance (ANOVA) was applied to test if BPE, plant biomass, $\mathrm{P}$ acquisition cost, plant-derived $\mathrm{C}$ in mesh bags, and mycorrhizal colonization differed between the control, N, P, and NP treatment within the inoculated mesocosms, where $\mathrm{N}$ addition and $\mathrm{P}$ addition were considered as the two independent factors. In case of significant interaction between $\mathrm{N}$ and $\mathrm{P}$ fertilization, the analysis was repeated as one-way considering four independent treatments. A similar approach was used for comparison of pasteurized vs. inoculated soil for the control and NP treatments. For GPP and $R_{\text {eco }}$, the model was extended with a random time-factor, according the subsequent measurement periods. This mixed model was applied on the residuals of the light response curves (for GPP) and temperature response curves (for $R_{\text {eco }}$ ) that were fitted for the pooled data. 


\section{RESULTS}

Fertilization with $\mathrm{N}$ and $\mathrm{P}$ increased $\mathrm{N}$ and $\mathrm{P}$ availability, respectively (Fig. 1; supply rates of additional nutrients are given in Appendix S1: Table S1). Considering the inoculated mesocosms only, seasonal cumulative GPP was four to six times higher in the P-fertilized (P and NP) vs. the P-limited ( $\mathrm{N}$ and control) mesocosms (Table 1, Fig. 2). $\mathrm{P}$ addition increased GPP, whereas $\mathrm{N}$ addition did not have a significant effect (Table 2). A similar trend was observed for $R_{\text {eco }}$, although the differences were smaller than for GPP, and N

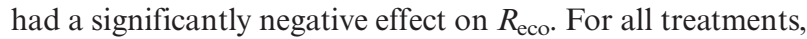
total cumulative $R_{\text {eco }}$ was higher than GPP, indicating a net C-source (Appendix S1: Fig. S1).

Fertilization effects on biomass production were in line with the effects observed for the $\mathrm{CO}_{2}$ fluxes, with biomass production being five to eight times higher in the P-fertilized mesocosms (on average $204 \pm 10 \mathrm{~g} \mathrm{C}^{2} \mathrm{~m}^{2}$ ) than in the P-limited mesocosms $\left(33 \pm 3 \mathrm{~g} \mathrm{C} / \mathrm{m}^{2}\right)$. In the P-limited mesocosms, root: shoot ratio (mean of $0.27 \pm 0.04$ ) was significantly higher $(P=0.02)$ than in the P-fertilized mesocosms $(0.17 \pm 0.02$ on average). Also in the share of cobs in the aboveground biomass, a significant $\mathrm{P}$ effect $(P<0.01)$ was found, with mean values of $70 \% \pm 1 \%$ and $59 \% \pm 1 \%$ for the P-limited and P-fertilized, respectively (Appendix S1: Table S2).
Because biomass production increased more in response to P fertilization than GPP, BPE was significantly higher in the P-fertilized mesocosms (Tables 1 and 2, Fig. 3). Although GPP and biomass production were slightly lower in the $\mathrm{N}$-fertilized mesocosms, the effects of $\mathrm{N}$ addition on biomass production and BPE were not statistically significant. We also found no interaction effect of $\mathrm{P}$ and $\mathrm{N}$ fertilization on biomass production or on BPE. Initially (when plants were four weeks old), the leaf $R_{\text {dark }} / A_{\max }$ ratio (Fig. 4) was significantly $(P<0.01)$ higher in the P-limited mesocosms (control and $\mathrm{N}$ ) as compared to the P-fertilized mesocosms (P and NP). During the second leaf measurement campaign (on eight-week-old plants), however, $R_{\text {dark }} /$ $A_{\max }$ was at a similar level for all treatments, and $R_{\mathrm{dark}} / A_{\max }$ was even slightly higher in the P-fertilized mesocosms. No N effect $(P=0.59)$ or $\mathrm{N} \times \mathrm{P}$ interaction effect was observed.

The absolute amount of plant-derived $\mathrm{C}$ in the mesh bags was slightly higher in the P-fertilized treatments. The significant correlation between PLFA 16:1 $\omega 5$ and plant derived C in mesh bags (Fig. 5) of the inoculated mesocosms further supports that the plant-derived $\mathrm{C}$ in the mesh bags originated primarily from AMF. As a fraction of GPP, however, plant-derived $\mathrm{C}$ was significantly smaller, about four to five times, compared to the P-limited treatments (Tables 1 and 2, Fig. 3). Also in terms the percentage of roots colonized a

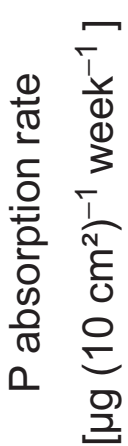

b

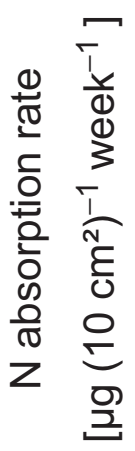

Control
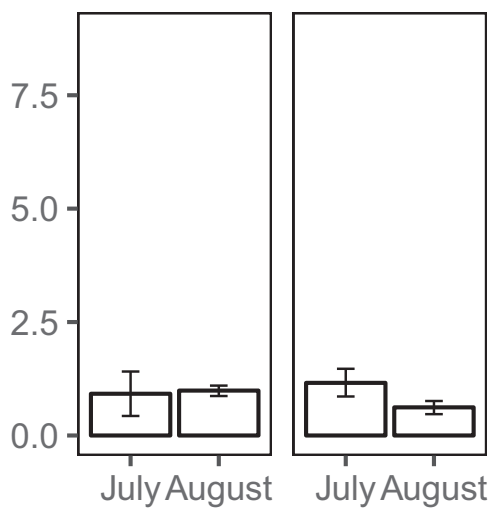

N
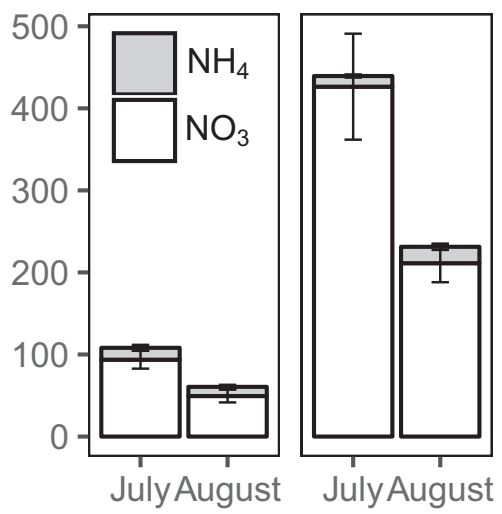

$\mathrm{N}$

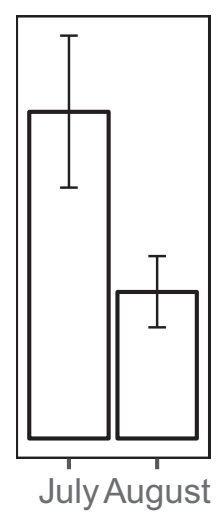

NP

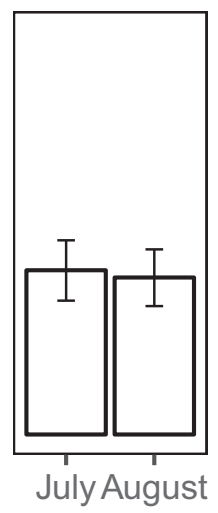

NP
$P$

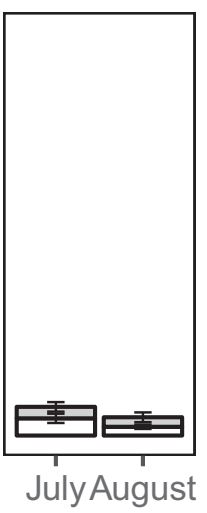

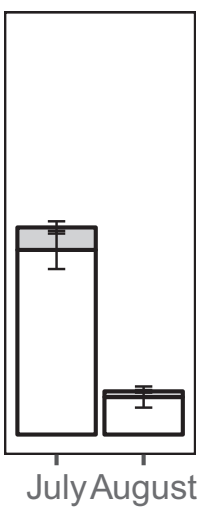

Control, past. NP, past.

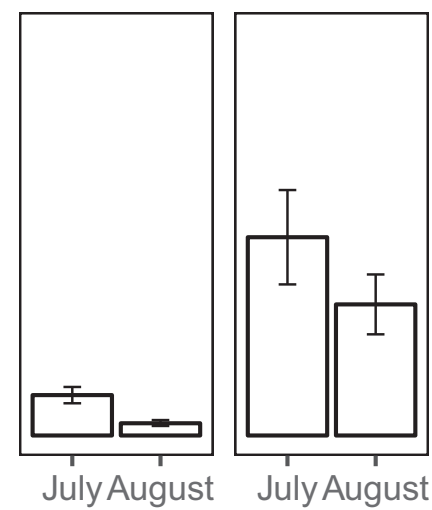

Control, past. NP, past.



FIG. 1. PRS(tm)-probe nutrient supply rate of (a) $\mathrm{P}$ and (b) $\mathrm{NO}_{3}-\mathrm{N}$ and $\mathrm{NH}_{4}-\mathrm{N}$ for July and August. past. = pasteurized. Error bars indicate standard error $(n=5)$. 
TABLE 1. Seasonal means of C fluxes, C pools, and mycorrhizal colonization in August.

\begin{tabular}{|c|c|c|c|c|c|c|c|c|c|c|c|c|c|c|c|c|c|c|c|}
\hline \multirow[b]{3}{*}{ Treatment } & \multicolumn{2}{|c|}{$\underset{\left.\left(\mathrm{g} \mathrm{C}^{\mathrm{GPP}}\right)^{2}\right)}{\mathrm{G}}$} & \multicolumn{2}{|c|}{$\begin{array}{c}R_{\mathrm{eco}} \\
\left(\mathrm{g} \mathrm{Clm}^{2}\right)\end{array}$} & \multicolumn{2}{|c|}{$\begin{array}{l}\text { Plant biomass } \\
\quad\left(\mathrm{g} \mathrm{C}^{2} \mathrm{~m}^{2}\right)\end{array}$} & \multirow[t]{2}{*}{ BPE $(\%)$} & \multicolumn{2}{|c|}{$\begin{array}{c}\mathrm{P} \\
\text { acquisition } \\
\text { cost } \\
(\mathrm{g} \mathrm{C} / \mathrm{g} \mathrm{P})\end{array}$} & \multicolumn{2}{|c|}{$\begin{array}{c}\text { Plant- } \\
\text { derived C } \\
\text { in mesh bags } \\
\left.\left(\mathrm{g} \mathrm{C}^{2}\right)^{2}\right)\end{array}$} & \multicolumn{2}{|c|}{$\begin{array}{c}\text { Plant- } \\
\text { derived } \\
\text { C:GPP }(\%)\end{array}$} & \multicolumn{6}{|c|}{$\begin{array}{l}\text { Mycorrhizal colonization } \\
\text { in roots }(\%)\end{array}$} \\
\hline & \multirow[b]{2}{*}{ Mean } & \multirow[b]{2}{*}{ SE } & \multirow[b]{2}{*}{ Mean } & \multirow[b]{2}{*}{ SE } & \multirow[b]{2}{*}{ Mean } & \multirow[b]{2}{*}{ SE } & & \multirow[b]{2}{*}{ Mean } & \multirow[b]{2}{*}{ SE } & \multirow[b]{2}{*}{ Mean } & \multirow[b]{2}{*}{ SE } & \multirow[b]{2}{*}{ Mean } & \multirow[b]{2}{*}{ SE } & \multicolumn{2}{|c|}{ Hyphae } & \multicolumn{2}{|c|}{ Arbuscules } & \multirow{2}{*}{\multicolumn{2}{|c|}{$\frac{\text { Vesicules }}{\text { Mean SE }}$}} \\
\hline & & & & & & & Mean & & & & & & & Mean & $\mathrm{SE}$ & Mean & $\mathrm{SE}$ & & \\
\hline \multicolumn{20}{|c|}{ Soil pasteurization and fertilization (not pasteurized, AMF inoculated) } \\
\hline Control & 123.2 & 85.1 & $206.3^{\mathrm{a}}$ & 33.0 & 39.0 & 1.8 & 31.71 .5 & 56 & 6 & 8.7 & 0.7 & $7.1^{\mathrm{b}}$ & 4.9 & 68.8 & 5.3 & 46.4 & 3.3 & 15.8 & 4.6 \\
\hline $\mathrm{N}$ & 87.5 & 87.4 & 176.6 & 22.8 & 26 & 2 & 29.92 .6 & 83 & 12 & 7.2 & 0 . & 8.3 & 8.3 & 64.6 & 3.4 & 36.6 & 4.2 & 20.0 & 1. \\
\hline $\mathrm{P}$ & 566.3 & 361.8 & 582.9 & 86.4 & 210.7 & 7.1 & $37.2 \quad 1.3$ & 19 & 3 & 9.9 & 1.3 & 1.7 & 1.1 & 41.4 & 10.3 & 16.4 & 6.4 & 6.8 & 4.2 \\
\hline NP & 520.9 & 230.5 & $573.4^{\mathrm{c}}$ & 61.4 & 197.2 & 12.3 & 37.92 .4 & 27 & 4 & 10.7 & 0.5 & $2.0^{\mathrm{b}}$ & 0.9 & 37.4 & 2.0 & 11.9 & 6.0 & 5.0 & 2.2 \\
\hline \multicolumn{20}{|l|}{ Pasteurized } \\
\hline Control & 35.7 & 173.9 & $176.2^{\mathrm{a}}$ & 41.5 & $2.9 \dagger$ & 0.2 & $\mathrm{n} / \mathrm{a} \dagger$ & $\mathrm{n} / \mathrm{a} \dagger$ & & 8.8 & 1.1 & $24.8^{\mathrm{a}}$ & 120.8 & 0 & 0 & 0 & 0 & 0 & 0 \\
\hline NP & 466.2 & 116.8 & $501.7^{\mathrm{b}}$ & 85.2 & 137.7 & 3.8 & 30.90 .9 & 43 & 4 & 13.7 & 1.3 & $2.9^{\mathrm{b}}$ & 0.8 & 0 & 0 & 0 & 0 & 0 & 0 \\
\hline
\end{tabular}

Notes: GPP, gross primary production; $R_{\text {eco }}$ ecosystem respiration; AMF, arbuscular mycorrhizal fungi; BPE, biomass production efficiency; SE, standard error; n/a, not applicable. Superscript letters indicate homogeneous groups as results from post-hoc analysis of oneway ANOVA (see Table 2), in case of a significant interaction in two-way ANOVA. In cases where an interaction was not significant, no post-hoc results were added. Given a single factor has a significant effect, the mean values indicate the direction of the difference.

$\dagger$ A major part of the plants in the pasteurized control treatment died during the season, resulting in a deviating low biomass harvest at the end of the season. BPE could therefore not be determined.

TABLE 2. P values from a two-way ANOVA for the effects of treatment on C fluxes, C pools, and mycorrhizal colonization.

\begin{tabular}{|c|c|c|c|c|c|c|c|c|c|c|}
\hline \multirow{2}{*}{ Treatment } & \multirow{2}{*}{ GPP } & \multirow{2}{*}{$R_{\text {eco }}$} & \multirow{2}{*}{$\begin{array}{c}\text { Plant } \\
\text { biomass }\end{array}$} & \multirow{2}{*}{ BPE } & \multirow{2}{*}{$\begin{array}{l}\text { P acquisition } \\
\text { cost }\end{array}$} & \multirow{2}{*}{$\begin{array}{l}\text { Plant-derived } \\
\mathrm{C} \text { in mesh bags }\end{array}$} & \multirow{2}{*}{$\begin{array}{c}\text { Plant-derived } \\
\text { C:GPP }\end{array}$} & \multicolumn{3}{|c|}{ Mycorrhizal colonization in roots } \\
\hline & & & & & & & & Hyphae & Arbuscules & Vesicules \\
\hline $\mathrm{N} \times \mathrm{P}$ & 0.15 & 0.64 & 0.97 & 0.63 & 0.20 & 0.15 & 0.30 & 0.99 & 0.62 & 0.39 \\
\hline $\mathrm{N}$ & 0.06 & $<0.01$ & 0.19 & 0.82 & 0.03 & 0.78 & 0.09 & 0.50 & 0.17 & 0.73 \\
\hline $\mathrm{P}$ & $<0.01$ & $<0.01$ & $<0.01$ & 0.01 & $<0.01$ & $<0.01$ & $<0.01$ & $<0.01$ & $<0.01$ & $<0.01$ \\
\hline Fertilization $\times$ Pasteurization & 0.08 & $<0.01$ & 0.20 & $\mathrm{n} / \mathrm{a}$ & $\mathrm{n} / \mathrm{a}$ & 0.15 & $<0.01$ & $\mathrm{n} / \mathrm{a}$ & $\mathrm{n} / \mathrm{a}$ & $\mathrm{n} / \mathrm{a}$ \\
\hline Fertilization & $<0.01$ & & $<0.01$ & $\mathrm{n} / \mathrm{a}$ & $\mathrm{n} / \mathrm{a}$ & $<0.01$ & & $\mathrm{n} / \mathrm{a}$ & $\mathrm{n} / \mathrm{a}$ & $\mathrm{n} / \mathrm{a}$ \\
\hline Pasteurization & $<0.01$ & & $<0.01$ & 0.06 & 0.02 & 0.12 & & $\mathrm{n} / \mathrm{a}$ & $\mathrm{n} / \mathrm{a}$ & $\mathrm{n} / \mathrm{a}$ \\
\hline
\end{tabular}

$P$ values in boldface type are significant $(P \leq 0.05)$.

a

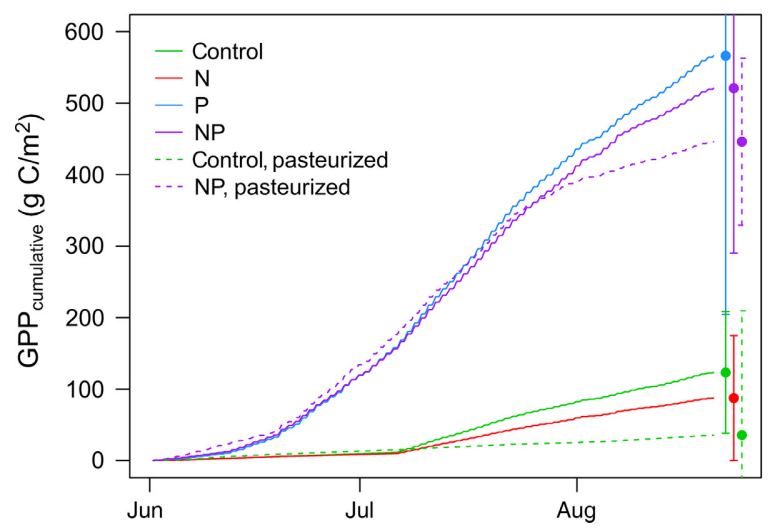

b

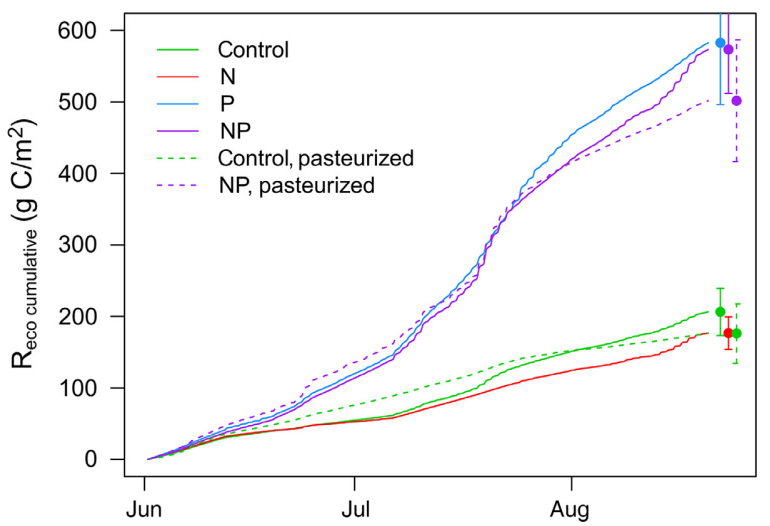

FIG. 2. Seasonal cumulative ecosystem-scale (a) gross primary productivity (GPP) and (b) ecosystem respiration, comprising autotrophic and heterotrophic respiration $\left(R_{\text {eco }}\right)$ for the different treatments. Total seasonal cumulative values are given with standard error bars $(n=5)$.

(with hyphae and both vesicules and arbuscules), the P-limited mesocosms showed a significantly higher mycorrhization than the P-fertilized mesocosms (Tables 1 and 2). The proxy for the $\mathrm{P}$ acquisition cost (root biomass plus plantderived $\mathrm{C}$ per total plant $\mathrm{P})$, was significantly $(P<0.01)$ higher in the P-limited mesocosms. N-addition had no significant effect on plant-derived $\mathrm{C}$ and root colonization.

Seasonal GPP was significantly affected by pasteurization. The pasteurized control treatment showed very low productivity with a GPP value about four times smaller than 


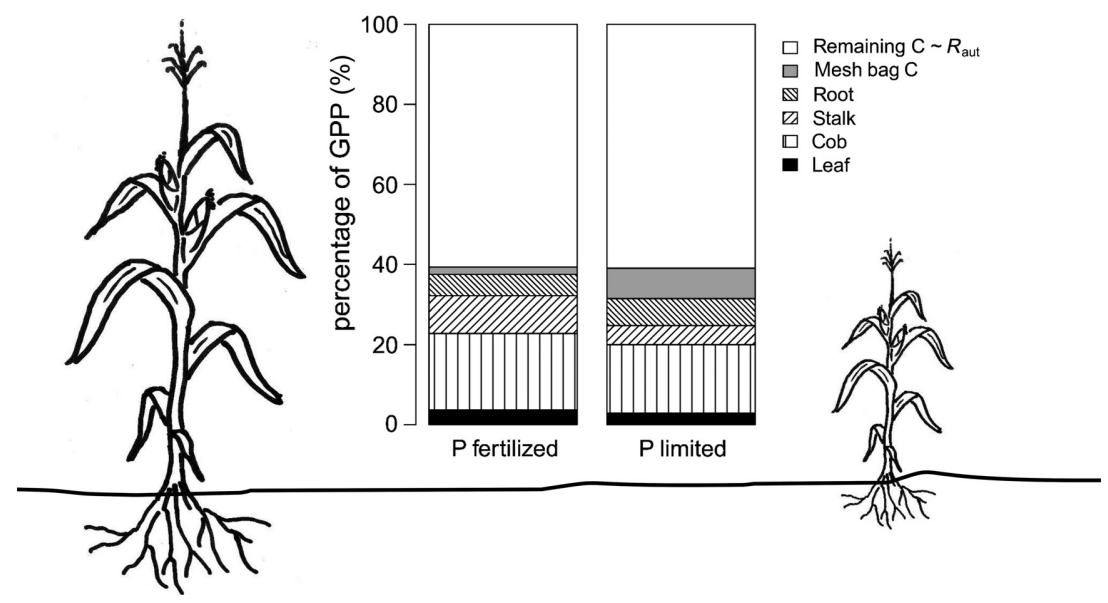

FIG. 3. Partitioning of plant biomass and mesh bag carbon of P-limited and P-fertilized inoculated mesocosms. Autotrophic respiration $\left(R_{\text {aut }}\right)$ was considered as the remainder part of GPP.
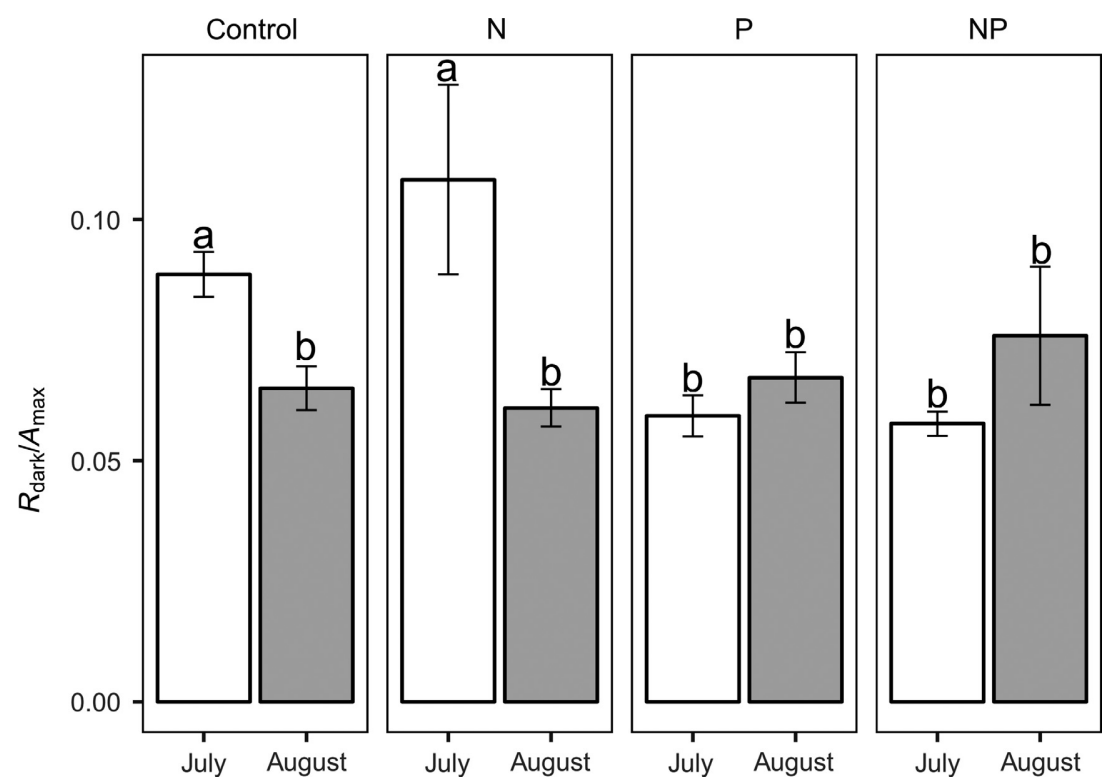

FIG. 4. Mean ratio of leaf-scaled respiration in the dark to maximal assimilation rate $\left(R_{\text {dark }} / A_{\max }\right)$ in July (white bars) and August (gray bars). Error bars indicate standard error $(n=7-15)$. Statistical analysis showed a significant $\mathrm{P}$ effect and $\mathrm{P} \times$ campaign interaction; different letters above bars indicate significant differences $(P \leq 0.05)$.

in the inoculated control mesocosms. When (NP) fertilized, the pasteurized mesocosms produced about $15 \%$ less than the inoculated mesocosms (Table 1, Fig. 2). Mesocosm respiration followed a similar pattern, but with smaller differences between the pasteurized and the inoculated mesocosms. About 50 times more end of season biomass was harvested from the pasteurized NP mesocosms than the pasteurized control mesocosms (Table 1; Appendix S1: Table S2). This was due to the minor biomass production in the latter control mesocosms, where a major proportion of plants had even died prematurely. BPE could therefore not be determined for the pasteurized control mesocosms. The comparison of BPE, as well as the $\mathrm{P}$ acquisition cost, between pasteurized and inoculated mesocosms is therefore restricted to the NP mesocosms. The mean value of BPE in the inoculated NP mesocosms $(37.9 \pm 2.4)$ was higher than in the pasteurized NP mesocosms $(30.9 \pm 0.9$; although the pasteurization effect was only borderline significant; Tables 1 and 2), the latter having a mean BPE similar to the non-P-fertilized inoculated mesocosms (29.9-31.7; Table 1). On the other hand, the cost of $\mathrm{P}$ acquisition was significantly higher in the pasteurized NP mesocosms than in the NP mesocosms with AMF $(P<0.01$; Table 2$)$. As expected, no AMF were detected in the plant roots of the pasteurized mesocosms (Table 1), viz. no mycorrhizal colonization, and also the mesh bags contained no 16:1 15 PLFAs or NLFAs. However, mesh bags in the pasteurized mesocosms did contain similar amounts of plant-derived carbon as their homologue inoculated mesocosms (Table 1). In the pasteurized fertilized (NP) treatment, this share was on average $2.9 \% \pm$ $0.8 \%$, in the same order of magnitude as the inoculated NP treatment $(2.0 \% \pm 0.9 \%)$. 


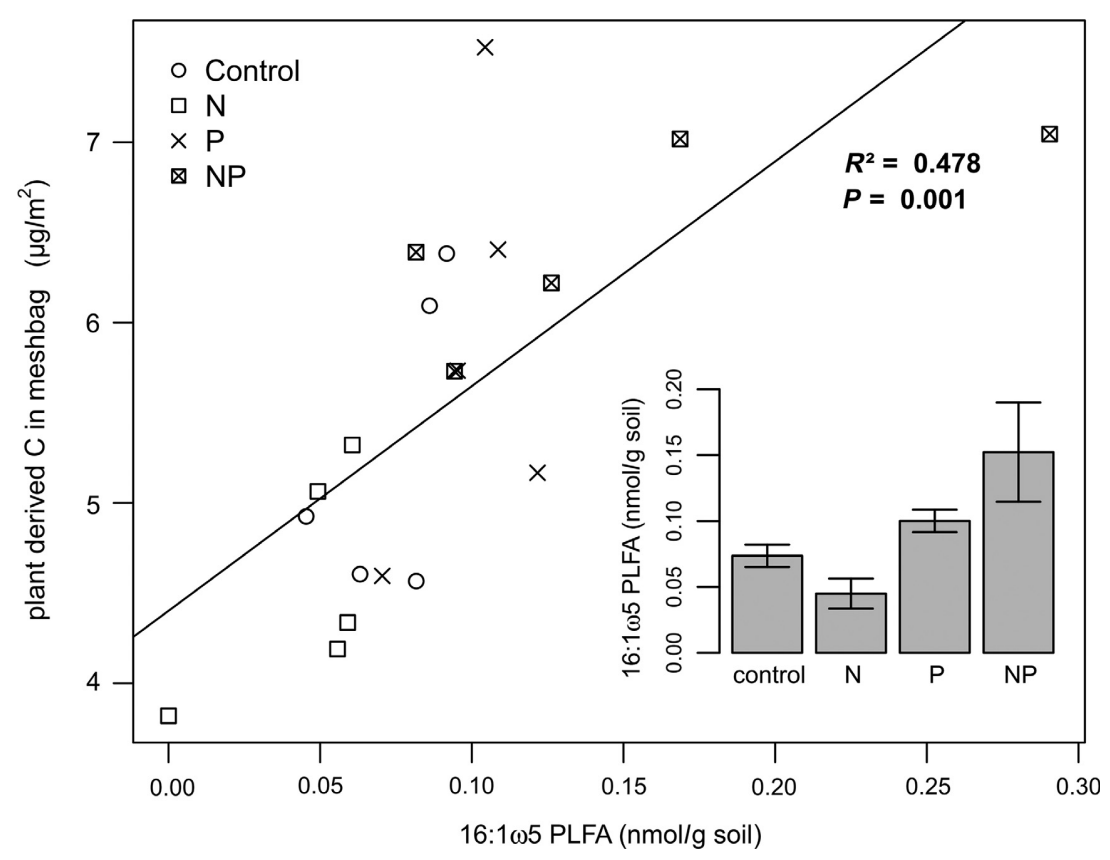

FIG. 5. Linear relation of plant-derived carbon (including mycorrhizal carbon and root exudates) in mesh bags to the specific $16: 1 \omega 5$ Phospholipid Fatty Acid (PLFA) in the inoculated mesocosms at the end of August. Inset bar plot shows mean (+SE) PLFA amount per treatment.

\section{Discussion}

The presence of AMF clearly influenced plant growth, and our results suggest that they were crucial for the plants to overcome $\mathrm{P}$ limitation in our system. In the absence of $\mathrm{P}$ addition, plants without AMF died prematurely whereas, in the mesocosms that did contain AMF, plants revived once mycorrhizae started growing, as indicated by the photosynthesis and respiration measurements at mesocosm scale and at leaf scale (Fig. 4). These results suggest that AMF were essential for plant survival under P-limited conditions. This is in line with results of previous studies showing that maize is a highly mycotrophic species (Hetrick et al. 1988, Hoeksema et al. 2010). The positive effect of the AMF required some time to occur, possibly corresponding to the phase where mycelium development with low compensating nutrient provision acts as a net $\mathrm{C}$ sink. Although no AMF were observed in the roots or in the mesh bags of the pasteurized mesocosms, similar amounts of plant-derived $\mathrm{C}$ as in the inoculated mesocosms were observed in the mesh bags. Although caution is needed when interpreting this indication of relative differences in amounts of root exudates, these results suggest that, in absence of AMF, plants produced a higher amount of exudates in order to attain nutrients (Marschener 1998, Hinsinger 2001, Dakora and Phillips 2002, Carvalhais et al. 2011).

The contribution of the mycorrhizal pathway to total phosphate uptake is also dependent on AMF-species identity (Munkvold et al. 2004, Koch et al. 2017). Among fungal species, the presently used $R$. irregularis, has been shown to suppress the expression of plant $\mathrm{P}$ transporters of the plant pathway the most (Bücking et al. 2012). In case of high nutrient availability, growth of AMF-associated plants might decrease (e.g., Peng et al. 1993, Colpaert et al. 1996), merely resulting from (1) the high $\mathrm{C}$ cost of the symbiosis for the plant that is not counterbalanced by a net gain in phosphate (Johnson et al. 1997) and/or (2) reduced phosphate uptake via the plant pathway that is not compensated for by an increased mycorrhizal uptake, leading to an overall phosphate deficiency for the plant (Smith et al. 2011). In our study on maize monocultures, however, the higher BPE in inoculated NP mesocosms $(37.9 \% \pm 2.4 \%)$ vs. the pasteurized NP mesocosms $(30.4 \pm 0.9 \%)$ indicates rather the opposite. Although this difference in BPE was only borderline significant, the absence of a negative effect indicates that also under apparently ample nutrients AMF did not act as a net $\mathrm{C}$ cost to the plants. On the contrary, AMF exerted a beneficial effect on plant biomass production, as our proxy for the $\mathrm{C}$ cost of $\mathrm{P}$ acquisition was significantly lower for NP than for NP pasteurized mesocosms. The AMF thus more than compensated for the $\mathrm{C}$ they received from their hosts, suggesting a positive influence of AMF beyond enhancing nutrient uptake in low nutrient environments. This is in accordance with previous studies showing that AMF presence can improve the efficiency of fertilizer uptake and limit nutrient leakage (Cozzolino et al. 2013), and that AMF can also play a role in protection against plant pathogens (Miransari 2011), thus reducing plant C losses.

In our experiment, the unfertilized soil was clearly P limited; an addition of $\mathrm{P}$ significantly increased plant productivity, whereas $\mathrm{N}$ addition did not. The lack of $\mathrm{N}$ limitation in the mesocosms, indicated by the lack of $\mathrm{N}$ effects on plant biomass production, BPE and most other measured parameters, precluded assessing potential effects of $\mathrm{N}$ limitation on $\mathrm{C}$ partitioning and on the role of AMF therein. In accordance with our hypothesis, biomass production increased more than GPP when P-limitation was relieved: BPE was significantly higher in the P-fertilized mesocosms vs. the P- 
limited mesocosms. Moreover, the P-induced increase in BPE (about $6 \%$ of GPP; Table 1, Fig. 3) was associated with a reduced partitioning to plant-derived $\mathrm{C}$ in the soil.

The positive relationship between PLFA and plantderived $\mathrm{C}$ in the mesh bags of the inoculated mesocosms, and the fact that PLFA amount was only 2-3 times higher in the P-fertilized mesocosms compared to the P-limited mesocosms whereas GPP was 4-5 times higher, indicate a higher partitioning to $\mathrm{AMF}$ in the inoculated P-limited mesocosms. These observations thus confirm the hypothesized role of mycorrhizal fungi, and $\mathrm{C}$ partitioning to nutrient acquiring processes in general, in determining nutrient effects on BPE. They also broadly agree with the trade-balance framework of mycorrhizal functioning as proposed by Johnson (2010); this framework states that considering N, P, and $\mathrm{C}$ limitation of both plants and their symbionts is key to understanding $\mathrm{C}$ investment in fungi and plant responses to mycorrhization. Under low-P conditions, growth of mycorrhizal fungi thus appeared primarily limited by low plant $\mathrm{C}$ assimilation, while the plants did invest a large fraction of these photosynthates to the AMF, which they needed for their P nutrition. Under N- and P-fertilized conditions, mycorrhizal growth was probably constrained by their effectivity in supplying plants with sufficient $\mathrm{P}$ to match plant demand and be rewarded with $\mathrm{C}$ accordingly, as plants could also rely more on their roots to take up the $\mathrm{N}$ and $\mathrm{P}$ that were ample. The increase in BPE in response to mycorrhization at high nutrient conditions, therefore suggests that maize is highly effective at directing its fungal allocation, as high $\mathrm{C}$, $\mathrm{N}$ and $\mathrm{P}$ conditions should, from a mycocentric point of view, favor a reduced mutualistic lifestyle (Johnson 2010, Kiers et al. 2011).

Also, the leaf scale flux measurements suggest a role for AMF in controlling C partitioning (Fig. 4); when mycorrhizal root colonization had not yet occurred or was still in its initial phase, early in the season, the ratio of $R_{\mathrm{dark}} / A_{\max }$ was higher in the P-limited mesocosms than in the P-fertilized mesocosms (Fig. 4). Such an increased C partitioning to plant respiration often occurs at limiting nutrient availability (Raich et al. 2014). For instance, plants can adapt to this lack of nutrients by retranslocating a greater fraction of N and P (Tilton 1977, Chapin and Kedrowski 1983) as a strategy to improve the efficiency of internal utilization of nutrients (Smith 2001). Retranslocation processes are energy expensive and thus come at a high respiratory cost, since enzymes that break down molecules and nutrient transporter molecules need to be produced (Killingbeck 2004), which might explain the initial increase of the $R_{\text {dark }} / A_{\text {max }}$ ratio in Plimited systems. However, the difference disappeared later in the season, and even tended to invert: the $R_{\mathrm{dark}} / A_{\max }$ ratio in the P-limited mesocosms decreased to a level slightly lower than in the P-fertilized mesocosms. This change over time corresponded well with the temporal pattern observed for mycorrhizal root colonization. Whereas no AMF were found in the plant roots sampled during the first leaf measurement campaign, AMF structures were abundant in roots sampled at the time of the second campaign (Table 1). Reduced stress because of increased nutrient uptake under P limitation presumably decreased leaf-level respiration compared to its assimilation. At the seasonal scale, partitioning of the approximated mesocosm-scaled $R_{\text {aut }}$ was very similar for
P-limited and P-fertilized mesocosms (both 61\%, Fig. 3). Although these are crude estimates (obtained from a mass balance approach using the plant-derived $\mathrm{C}$ in the mesh bags, which is merely indicative of relative treatment differences and does probably not accurately represent absolute amounts of root exudation), they confirm that the increases in BPE were indeed most likely due to shifts in $\mathrm{C}$ partitioning to $\mathrm{AMF}$ and not to altered partitioning to $R_{\text {aut }}$.

Our results confirm the assumption that plants invest a larger fraction of their $\mathrm{C}$ in $\mathrm{AMF}$ when nutrient availability is low (Vicca et al. 2012). AMF contribute to nutrient uptake by plants (Mosse and Phillips 1971, Parniske 2008, Smith and Read 2008) and are typically more abundant when plants are more limited by nutrient availability (Treseder 2004). Vice versa, when nutrient availability increases, AMF abundance generally decreases since plants allocate carbohydrates elsewhere and AMF become C-limited (Read 1991). The present study considered only the AMF-C retrieved from their biomass, and thus ignores mycorrhizal respiration. Hence, mycorrhizal $\mathrm{C}$ use was underestimated, both in absolute amounts and as percentage of GPP. Studies on mycorrhizal respiration are scarce due to the difficulties in its quantification. The majority of existing studies is conducted on annual crops and report a mycorrhizal respiration of 1 to 5\% of GPP (Jakobsen and Rosendahl 1990, Heinemeyer et al. 2006, Moyano et al. 2007, Tomè et al. 2016).

\section{Conclusion}

The results of our experimental study emphasize the modulating roles of nutrient availability and mycorrhizal fungi in terrestrial C cycling and sequestration (Wieder et al. 2015, Terrer et al. 2016, 2018). Specifically, our results confirm that the BPE of plants increases with increasing nutrient availability and to the best of our knowledge demonstrate for the first time with experimental data that reduced carbon partitioning to mycorrhizal fungi is the key underlying mechanism. Furthermore, for well-fertilized conditions, results of the NP treatments suggest that the benefit of nutrient uptake via mycorrhizal symbionts allows for higher GPP and BPE than via other mechanisms.

\section{ACKNOWLEDGMENTS}

This research was supported by the Research Foundation - Flanders (FWO), by the European Research Council grant ERC-SyG610028 IMBALANCE-P, by the ClimMani COST Action (ES1308) and by Methusalem funding of the Research Council UA. M. S. Verlinden and S. Vicca are post-doctoral fellows of the Fund for Scientific Research - Flanders (FWO). We gratefully acknowledge Fred Kockelbergh and Marc Wellens for technical support; Bart Hellemans, Lin Leemans, and Eddy De Smet for logistic support at the field site; Miguel Portillo Estrada for laboratory analyses and Erik Fransen and Ella Roelant for statistical advice. Authors M. S. Verlinden and A. Ven equally contributed to this manuscript.

\section{Literature Cited}

Atkin, O. K., I. Scheurwater, and T. L. Pons. 2007. Respiration as a percentage of daily photosynthesis in whole plants is homeostatic at moderate, but not high, growth temperatures. New Phytologist 174:367-380.

Balesdent, J., A. Mariotti, and B. Guillet. 1987. Natural ${ }^{13} \mathrm{C}$ abundance as a tracer for studies of soil organic matter dynamics. Soil Biology and Biochemistry 19:25-30. 
Birgander, J., J. Rousk, and P. A. Olsson. 2017. Warmer winters increase the rhizosphere carbon flow to mycorrhizal fungi more than to other microorganisms in a temperate grassland. Global Change Biology 23:5372-5382

Brundrett, M. N., B. D. Bougher, B. Dell, T. Grove, and N. Malajczuk. 1996. Working with mycorrhizas in forestry and agriculture. Australian Centre for International Agricultural Research, Canberra, Australia.

Bücking, H., E. Liepold, and P. Ambilwade. 2012. The role of the mycorrhizal symbiosis in nutrient uptake of plants and the regulatory mechanisms underlying these transport processes. Pages 108-138 in N. K. Dhal, and S. C. Sahu, editors. Plant science. InTech, Rijeka, Croatia.

Buendía, C., S. Arens, T. Hickler, S. I. Higgins, P. Porada, and A. Kleidon. 2014. On the potential vegetation feedbacks that enhance phosphorus availability - insights from a process-based model linking geological and ecological timescales. Biogeosciences 11:3661-3683

Campbell, C., L. Atkinson, J. Zaragoza-Castells, M. Lundmark, O. Atkin, and V. Hurry. 2007. Acclimation of photosynthesis and respiration is asynchronous in response to changes in temperature regardless of plant functional group. New Phytologist 176: 375-389.

Carvalhais, L. C., P. G. Dennis, D. Fedoseyenko, M. Hajirezaei, R. Borriss, and N. von Wirén. 2011. Root exudation of sugars, amino acids, and organic acids by maize as affected by nitrogen, phosphorus, potassium, and iron deficiency. Journal of Plant Nutrition and Soil Science 174:3-11.

Chapin, F. S. III, and R. A. Kedrowski. 1983. Seasonal changes in nitrogen and phosphorus fractions and autumn retranslocation in evergreen and deciduous taiga trees. Ecology 64:376-391.

Colpaert, J. V., A. Van Laere, and J. A. Van Assche. 1996. Carbon and nitrogen allocation in ectomycorrhizal and non-mycorrhizal Pinus sylvestris L. seedlings. Tree Physiology 16:787-793.

Courty, P. E., M. Buée, A. G. Diedhioua, P. Frey-Klett, F. Le Tacon, F. Rineau, M.-P. Turpault, S. Uroz, and J. Garbaye. 2010. The role of ectomycorrhizal communities in forest ecosystem processes: new perspectives and emerging concepts. Soil Biology and Biochemistry 42:679-698.

Cozzolino, V., V. Di Meo, and A. Piccolo. 2013. Impact of arbuscular mycorrhizal fungi applications on maize production and soil phosphorus availability. Journal of Geochemical Exploration 129:40-44

Dakora, F. D., and D. A. Phillips. 2002. Root exudates as mediators of mineral acquisition in low-nutrient environments. Plant and Soil 245:35-47.

De Boeck, H. J., C. M. Lemmens, S. Vicca, J. Van den Berge, S. Van Dongen, I. A. Janssens, R. Ceulemans, and I. Nijs. 2007. How do climate warming and species richness affect $\mathrm{CO}_{2}$ fluxes in experimental grasslands? New Phytologist 175:512-522.

DeLucia, E. H., J. E. Drake, R. B. Thomas, and M. GonzalezMeler. 2007. Forest carbon use efficiency: Is respiration a constant fraction of gross primary production? Global Change Biology 13:1157-1167.

Dewar, R. C., B. E. Medlyn, and R. E. McMurtrie. 1998. A mechanistic analysis of light and carbon use efficiencies. Plant, Cell and Environment 21:573-588.

Dijkstra, F. A., D. J. Augustine, P. Brewer, and J. C. von Fischer. 2012. Nitrogen cycling and water pulses in semiarid grasslands: Are microbial and plant processes temporally asynchronous? Oecologia 170:799-808.

Frostegård, Å., A. Tunlid, and E. Bååth. 1993. Phospholipid fatty acid composition, biomass, and activity of microbial communities from two soil types experimentally exposed to different heavy metals. Applied and Environmental Microbiology 59:3605-3617.

Giovannetti, M., and B. Mosse. 1980. An evaluation of techniques for measuring vesicular arbuscular mycorrhizal infection in roots. New Phytologist 84:489-500.

Heinemeyer, A., P. Ineson, N. Ostle, and A. H. Fitter. 2006. Respiration of the external mycelium in the arbuscular mycorrhizal symbiosis shows strong dependence on recent photosynthates and acclimation to temperature. New Phytologist 171:159-170.

Hetrick, B. A. D., D. G. Kitt, and G. T. Wilson. 1988. Mycorrhizal dependence and growth habit of warn-season and cool-season tallgrass prairie plants. Canadian Journal of Botany 66:1376-1380.

Hinsinger, P. 2001. Bioavailability of soil inorganic P in the rhizosphere as affected by root-induced chemical changes: a review. Plant and Soil 237:173-195.

Hobbie, E. A. 2006. Carbon allocation to ectomycorrhizal fungi correlates with belowground allocation in culture studies. Ecology 87:563-569.

Hoefnagel, M. H. N., O. K. Atkin, and J. T. Wiskich. 1998. Interdependence between chloroplasts and mitochondria in the light and the dark. Biochimica et Biophysica Acta 1366:235-255.

Hoeksema, J. D., et al. 2010. A meta-analysis of context-dependency in plant response to inoculation with mycorrhizal fungi. Ecology Letters 13:394-407.

Jakobsen, I., and L. Rosendahl. 1990. Carbon flow into soil and external hyphae from roots of mycorrhizal cucumber plants. New Phytologist 115:77-83.

Johnson, N. C. 2010. Resource stoichiometry elucidates the structure and function of arbuscular mycorrhizas across scales. New Phytologist 185:631-647.

Johnson, N. C., J. H. Graham, and F. A. Smith. 1997. Functioning of mycorrhizal associations along the mutualism-parasitism continuum. New Phytologist 135:575-586.

Kiers, E. T., et al. 2011. Reciprocal rewards stabilize cooperation in the mycorrhizal symbiosis. Science 333:880-882.

Killingbeck, K. T. 2004. Nutrient resorption. Pages 215-226 in L. D. Noodén, editor. Plant cell death processes. Elsevier Science Academic Press, San Diego, California, USA.

Koch, A. M., P. M. Antunes, H. Maherali, and J. N. Klironomos. 2017. Evolutionary asymmetry in the mycorrhizal symbiosis. New Phytologist 214:1330-1337.

Kuzyakov, Y. 2006. Sources of $\mathrm{CO}_{2}$ efflux from soil and review of partitioning methods. Soil Biology and Biochemistry 38:425-448.

Le Quéré, C., et al. 2016. Global carbon budget 2016. Earth System Science Data 8:605-649.

Lilleskov, E. A., T. J. Fahey, T. R. Horton, and G. M. Lovett. 2002. Belowground ectomycorrhizal fungal community change over a nitrogen deposition gradient in Alaska. Ecology 83:104-115.

Litton, C. M., J. W. Raich, and M. G. Ryan. 2007. Carbon allocation in forest ecosystems. Global Change Biology 13:2089-2109.

Loveys, B. R., L. J. Atkinson, D. J. Sherlock, R. L. Roberts, A. H. Fitter, and O. K. Atkin. 2003. Thermal acclimation of leaf and root respiration: an investigation comparing inherently fast- and slow-growing plant species. Global Change Biology 9:895-910.

Marschener, H. 1998. Role of root growth, arbuscular mycorrhiza, and root exudates for the efficiency in nutrient acquisition. Field Crops Research 56:203-207.

May, W. E., S. S. Malhi, C. B. Holzapfel, B. X. Nybo, J. J. Schoenau, and G. P. Lafond. 2012. The effects of potassium and chloride nutrition on seed yield of annual canarygrass. Agronomy Journal 104:1023-1031.

Miransari, M. 2011. Mycorrhizal fungi and ecosystem efficiency. Botanical research and practices. Nova Science Publishers, New York, New York, USA.

Mosse, B., and J. M. Phillips. 1971. The influence of phosphate and other nutrients on the development of vesicular-arbuscular mycorrhiza in culture. Microbiology 69:157-166.

Moyano, F., W. Kutsch, and E. Schulze. 2007. Response of mycorrhizal, rhizosphere and soil basal respiration to temperature and photosynthesis in a barley field. Soil Biology and Biochemistry 39:843-853.

Munkvold, L., R. Kjoller, M. Vestberg, S. Rosendahl, and I. Jakobsen. 2004. High functional diversity within species of arbuscular mycorrhizal fungi. New Phytologist 164:357-364.

Olsson, P. A., and A. Johansen. 2000. Lipid and fatty acid composition of hyphae and spores of arbuscular mycorrhizal fungi at different growth stages. Mycological Research 104:429-434. 
Olsson, P. A., and N. C. Johnson. 2005. Tracking carbon from the atmosphere to the rhizosphere. Ecology Letters 8:1264-1270.

Parniske, M. 2008. Arbuscular mycorrhiza: the mother of plant root endosymbioses. Nature Reviews Microbiology 6:763-775.

Peng, S., D. M. Eissenstat, J. H. Graham, K. Williams, and N. C. Hodge. 1993. Growth depression in mycorrhizal citrus at highphosphorus supply. Plant Physiology 101:1063-1071.

Raich, J. W., H. Lambers, and D. J. Oliver. 2014. Respiration in terrestrial ecosystems. Pages 613-649 in H. D. Holland, and K. K. Turekian, editors. Treatise on geochemistry. Second edition, Volume 10. Elsevier, Oxford, UK.

Read, D. J. 1991. Mycorrhizas in ecosystems. Experientia 47:376391.

Reich, P. B., M. B. Walters, D. S. Ellsworth, J. M. Vose, J. C. Volin, C. Gresham, and W. D. Bowman. 1998. Relationships of leaf dark respiration to leaf nitrogen, specific leaf area and leaf life-span: a test across biomes and functional groups. Oecologia 114:471-482.

Roy, R. N., A. Finck, G. J. Blair, and H. L. S. Tandon. 2006. Plant nutrition for food security. A guide for integrated nutrient management. Food and Agriculture Organization of the United Nations, Rome, Italy.

Smith, F. W. 2001. Plant responses to nutritional stress. Pages 249 269 in M. J. Hawkesford, and P. Buchner, editors. Molecular analysis of plant adaptation to the environment. Kluwer Academic Publishers, Dordrecht, The Netherlands.

Smith, S. E., and D. J. Read. 2008. Mycorrhizal symbiosis. Third edition. Academic Press, London, UK.

Smith, S. E., I. Jakobsen, M. Grønlund, and F. A. Smith. 2011. Roles of arbuscular mycorrhizas in plant phosphorus nutrition: interactions between pathways of phosphorus uptake in arbuscular mycorrhizal roots have important implications for understanding and manipulating plant phosphorus acquisition. Plant Physiology 156:1050-1057.

Staddon, P. L., C. B. Ramsey, N. Ostle, P. Ineson, and A. H. Fitter. 2003. Rapid turnover of hyphae of mycorrhizal fungi determined by AMS microanalysis of ${ }^{14} \mathrm{C}$. Science 300:1138-1140.

Temminghoff, E. J. M., and V. J. G. Houba. 2004. Plant analysis procedures. Springer, Dordrecht, The Netherlands.

Terrer, C., S. Vicca, B. A. Hungate, R. P. Phillips, and I. C. Prentice. 2016. Mycorrhizal association as a primary control of the $\mathrm{CO}_{2}$ fertilization effect. Science 353:72-74.
Terrer, C., S. Vicca, B. D. Stocker, B. A. Hungate, R. P. Phillips, P. B. Reich, A. C. Finzi, and I. C. Prentice. 2018. Ecosystem responses to elevated $\mathrm{CO}_{2}$ governed by plant-soil interactions and the cost of nitrogen acquisition. New Phytologist 217:507-522.

Tilton, D. L. 1977. Seasonal growth and foliar nutrients of Larix laricina in three wetland ecosystems. Canadian Journal of Botany 55:1291-1298.

Tomè, E., M. Ventura, S. Folegot, D. Zanotelli, L. Montagnani, T. Mimmo, G. Tonon, M. Tagliavini, and F. Scandellari. 2016. Mycorrhizal contribution to soil respiration in an apple orchard. Applied Soil Ecology 101:165-173.

Treseder, K. K. 2004. A meta-analysis of mycorrhizal responses to nitrogen, phosphorus, and atmospheric $\mathrm{CO}_{2}$ in field studies. New Phytologist 164:347-355.

Turnbull, M. H., D. T. Tissue, K. L. Griffin, S. J. Richardson, D. A. Peltzer, and D. Whitehead. 2005. Respiration characteristics in temperate rainforest tree species differ along a long-term soildevelopment chronosequence. Oecologia 143:271-279.

Van Aarle, I. M., and P. A. Olsson. 2003. Fungal lipid accumulation and development of mycelial structures by two arbuscular mycorrhizal fungi. Applied Environmental Microbiology 69:6762-6767.

van Oijen, M., A. Schapendonk, and M. Höglind. 2010. On the relative magnitudes of photosynthesis, respiration, growth and carbon storage in vegetation. Annals of Botany 105:793-797.

Vicca, S., P. Serrano-Ortiz, H. J. De Boeck, C. M. H. M. Lemmens, I. Nijs, R. Ceulemans, A. S. Kowalski, and I. A. Janssens. 2007. Effects of climate warming and declining species richness in grassland model ecosystems: acclimation of $\mathrm{CO}_{2}$ fluxes. Biogeosciences 4:27-36.

Vicca, S., et al. 2012. Fertile forests produce biomass more efficiently. Ecology Letters 15:520-526.

Vierheilig, H., P. Schweiger, and M. Brundrett. 2005. An overview of methods for the detection and observation of arbuscular mycorrhizal fungi in roots. Physiologia Plantarum 125:393-404.

Wallander, H., et al. 2013. Evaluation of methods to estimate production, biomass and turnover of ectomycorrhizal mycelium in forests soils-a review. Soil Biology and Biochemistry 57:10341047.

Wieder, W. R., C. C. Cleveland, W. K. Smith, and K. Todd-Brown. 2015. Future productivity and carbon storage limited by terrestrial nutrient availability. Nature Geoscience 8:441-445.

\section{SUPPORTING INFORMATION}

Additional supporting information may be found in the online version of this article at http://onlinelibrary.wiley.com/doi/10.1002/ecy. 2502/suppinfo 